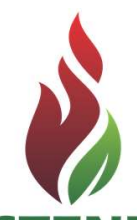

SUSTENERE

Publishing Corporation
ZRBADM

Journals Homepage:

www.sustenere.co/journals

\section{A CONFLUÊNCIA METODOLÓGICA NO ESTUDO DE DEFINIÇÃO DA FORMA DE REALIZAR P\&D}

\section{RESUMO}

O tema de inovação deixou de configurar uma opção para as organizações passando a ser um requisito obrigatório institucional e legitimizador junto ao setor econômico ao qual a organização se vincula. O centro do debate foi deslocado para a questão da forma de inovar e de pesquisar, notadamente do processo decisório no tocante a formas de conduzir P\&D que se restringe a três alternativas - P\&D interno, externo ou combinando o interno com o externo, em virtude do expressivo aumento do custo de realizar destas atividades. Constata-se que o processo de P\&D faculta diversas abordagens à luz de mais relevantes teorias organizacionais, apoiados em diferentes paradigmas, axiomas e ideologias (visões do mundo), o que, por sua vez, exige uma reflexão sobre a articulação metodológica do tema em tela. $O$ presente texto tem por finalidade realizar uma análise das alternativas metodológicas e demonstrar as possibilidades de sua articulação dentro da pesquisa proposta. Trata-se de um ensaio teórico, baseado em robusta revisão de textos, tanto de autores clássicos como contemporâneos que versam sobre o referido tema. O resultado da análise facultou identificar os critérios que devem ser observados ao longo do processo decisório que visa definir a forma de realizar as atividades de P\&D dentro da organização.

PALAVRAS-CHAVES: Delineamento metodológico; Inovação; Pesquisa e Desenvolvimento.

\section{THE METHODOLOGICAL CONFLUENCE IN THE DEFINITION STUDY OF HOW TO CARRY OUT R \& D}

\section{ABSTRACT}

The theme of innovation left to set an option for organizations becoming a mandatory requirement and institutional legitimizing with the economic sector to which the organization is linked. The heart of the debate was moved to the question of how to innovate and research, notably the decision-making process on ways of conducting $R$ \& $D$ which is limited to three alternatives - internal $R$ \& $D$, external or combining the internal with the external, by virtue of significant increase in the cost of performing these activities. It appears that the $R \& D$ process provides various approaches in the light of the most relevant organizational theories, supported by different paradigms, axioms and ideologies (worldviews), which, in turn, requires a reflection on the methodological integration theme in screen. It is a theoretical essay, based on robust review of texts, both classic and contemporary authors that deal with the said topic. This paper aims to undertake a review of methodological alternatives and demonstrate the possibilities of their articulation of the proposed research

KEYWORDS: Methodological Design; Innovation; Research and Development
Revista Brasileira de

Administração Científica,

Aquidabã, v.6, n.1, Jan, Fev, Mar, Abr, Mai, Jun 2014

ISSN 2179-684X

SECTION: Articles

TOPIC: Empreendedorismo e Inovação

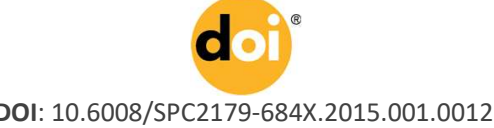

Dusan Schreiber

Universidade Feevale, Brasil http://lattes.cnpq.br/5088882022022801 dusan@feevale.br

Received: 28/01/2015

Approved: 14/10/2015

Reviewed anonymously in the process of blind peer

Referencing this:

SCHREIBER, D.. A confluência metodológica no estudo de definição da forma de realizar $P \& D$. Revista

Brasileira de Administração Científica, Aquidabã, v.6, n.1, p.197-215, 2015. DO :

http://dx.doi.org/10.6008/SPC2179$684 X .2015 .001 .001$ 


\section{INTRODUÇÃO}

No final da década de oitenta e durante os anos noventa, do século passado, foi verificado o acirramento da competição no ambiente corporativo e a consequente redução das margens operacionais, em virtude da globalização dos mercados. Da produção de altos volumes as organizações passaram a focar a produção de itens de valor unitário agregado mais alto, impactando na necessidade de revisão de conceitos de organização industrial. Novos processos organizacionais foram desenhados, enfatizando características como flexibilidade, criatividade e descentralização. O novo tipo de organização destacou a importância do conhecimento especializado como diferencial competitivo, e passou a adotar estratégias que privilegiam a adaptação contextual e situacional, de acordo com a estratificação de consumidores em nichos globalmente distribuídos (ORTIZ, 2003).

Destarte evidencia-se a importância do P\&D industrial, dentro do qual a inovação voltada ao portfolio de produtos ou serviços é representada pela incorporação do conhecimento organizacional para satisfazer as necessidades de seus clientes atuais ou para criar novas necessidades (MORT, 2001), tipificando, desta forma, a relação entre teoria e prática (MARDSEN, 2001). Integrada ao ambiente organizacional, a área de P\&D passou a fazer parte do sistema de significados organizacionais, constituindo um de seus elementos simbólicos e normativos, reforçados por processos regulatórios (SCOTT, 1994). Como uma das fontes mais destacadas de geração do conhecimento, a área de P\&D representa o repositório do recurso competitivo de valor agregado mais relevante e oferece a condição ímpar de diferenciação (MADHOK, 1996; LANGLOIS, 2003).

$\mathrm{O}$ processo de $\mathrm{P} \& \mathrm{D}$, bem como as metodologias que o fundamentam, especialmente as formas de registros sistemáticos do conhecimento adquirido por meio de testes e de seus resultados, além de manualização de regras e procedimentos, entre outros, mantêm e reforça a dominação através de características impessoais, baseadas na racionalidade e no conhecimento técnico (WEBER, 1999). Dentre as demais atividades organizacionais evidencia-se a característica essencial de criação organizada, pelo reconhecimento dos elementos mais alinhados com o foco da pesquisa, combinando a ação não estruturada, mudança, projetabilidade, situação e campo abstrato (COOPER, 1976).

Esta realidade complexa e multifacetada da área de P\&D reflete-se no processo decisório que procura definir a forma de sua realização (externa, interna ou combinada). Ao mesmo tempo em que são considerados elementos objetivos emergem variáveis subjetivas que podem alterar a percepção da realidade interpretada com base em fatos e evidências aparentemente destituídos de subjetividade. Esta constatação baseia-se no reconhecimento de que o conjunto de normas, valores, regras, rotinas e processos organizacionais, explícitos e implícitos, vinculados, combinados e permeados em um conjunto de expressões ativas e afetivas dos indivíduos da 
organização, suas percepções, tanto de natureza objetiva como subjetiva, individual ou grupalmente, representam a cultura organizacional.

Em face das evidências da complexidade do ambiente organizacional e, em especial, da área de $P \& D$, entende-se que a condução de pesquisa do referido processo decisório não pode se restringir apenas a uma determinada concepção metodológica, quantitativa ou qualitativa, apoiada em um axioma e paradigma interpretativo, mas, isto sim, exige um tratamento metodológico que possa representar de forma mais completa a realidade organizacional permeada tanto por elementos objetivos como subjetivos. Com o intuito de demonstrar não apenas a necessidade como também a viabilidade de combinação de métodos de pesquisa, com o fim de atender o propósito de representar de forma mais fiel possível a realidade estudada, será apresentado na seção um o contexto do ambiente de inovação nas organizações, na segunda seção será abordado o debate dos paradigmas na representação da realidade, sendo sequenciado pelo tema da seção três, que apresentará diversas correntes teóricas que tratam da possibilidade de confluência dos diversos métodos de pesquisa. Na seção quatro o tema abordado será finalizado com as considerações finais do autor.

\section{DISCURSÃO TEÓRICA}

\section{Contexto do Ambiente de Inovação nas Organizações}

Inicialmente se faz necessária a apresentação de algumas bases conceituais com o objetivo de introduzir o tema em análise e facilitar, desta forma, o acompanhamento da construção argumentativa do presente texto. Com o fim de contextualizar o tema de P\&D, central para o presente ensaio, é importante iniciar pelo tema de inovação para depois retratar as atividades de P\&D. Do ponto de vista da gestão e com os olhos voltados para o mercado a inovação é definida por Westwood e Sekine (1988) como o processo pelo qual às vezes as invenções são transformadas em produtos ou sistemas economicamente sustentáveis. A sustentabilidade econômica do produto novo está vinculada diretamente ao conceito de utilidade como destaca Stokes (2005), ao apresentar o Quadrante de Pasteur, fundamentado em pesquisa básica inspirada na sua utilização, ressaltando quatro questões conceituais relacionadas à pesquisa: caracterização da pesquisa, os objetivos que devem ser levados em conta, possibilidade de redução das duas dimensões a uma e tempo até a aplicação.

A abordagem de Stokes (2005) foi complementada por O'Connor e Ayres (2005) que destacaram três etapas no processo de pesquisa e desenvolvimento de produtos novos para o mercado: descoberta, centrada em conceito e composta pelas atividades de pesquisa básica, pesquisa interna e pesquisa externa por meio de licenciamento, aquisição ou investimento; incubação, focada em experimentação e segmentada em atividades como a realização de testes técnicos, testes de mercado, criação com base no mercado, alinhamento estratégico; aceleração, 
que visa a comercialização do produto no mercado e se caracteriza por três etapas, a saber, definição do foco, avaliação da resposta do mercado e investimento na fabricação do produto.

As contribuições de Stokes (2005); O'Connor e Ayres (2005) facultam a percepção da ampliação da função de P\&D dentro da organização, com a inclusão de "uso" ou "utilidade" que transcende a mera viabilidade econômica, pois permite à organização visualizar novos benefícios das atividades vinculadas a P\&D. Trata-se de novas competências e conhecimentos, decorrentes das atividades de pesquisa e desenvolvimento, realizadas na interação com as demais áreas e unidades organizacionais, visão compartilhada por McNulty e Whittington (1992) que destacam a necessidade de desenvolvimento de competência, dos técnicos de P\&D, para interagir com clientes e com fornecedores (BOYLE et al., 2005).

Um dos autores que analisou a opção de realização externa das atividades de P\&D é Howells (1999) que parte de uma visão mais ampla ao destacar quatro razões para justificar a decisão: o crescimento, tanto absoluto como relativo da externalização de P\&D em países industrializados, tornando, desta forma, este fenômeno cada vez mais representativo; a abordagem de P\&D como uma função e atividade corporativa que está em mudança e, portanto, não pode mais contar apenas com conhecimento interno; a relevância do papel de P\&D na criação e desenvolvimento do mercado de pesquisa; o crescimento de organizações voltadas à execução de contratos de P\&D.

Existem evidências de que o tema tem merecido atenção de pesquisadores tanto no Brasil como no exterior. Autores brasileiros, como Dagnino (2003) contribuem para o debate ao verificar que as empresas brasileiras têm resistência em investir no processo de inovação e quando o fazem, preferem incorporar a tecnologia pronta, via importação de máquinas e equipamentos, reduzindo, desta forma, a incerteza e o risco de investimento em P\&D. Entendem que nesta situação se destaca a importância dos programas governamentais de fomento por oferecerem a oportunidade para as empresas que vierem a investir em P\&D o compartilhamento dos riscos e redução dos custos. Cabe destacar que os conceitos até aqui apresentados enfatizam a expansão da função de P\&D e sua integração ao universo organizacional, criando, desta forma, um conceito multidisciplinar da área, onde cada uma das unidades organizacionais pode contribuir para o desenvolvimento de novos produtos e processos operacionais. No entanto sabe-se que existem vantagens estratégicas que esta interação das diversas unidades organizacionais pode oferecer para a consolidação das competências, da aprendizagem, da estratégia, entre outras.

A primeira e mais recorrente explicação, tecida à luz da teoria de custos de transação, decorrente de teoria da firma de Coase (1937), recomenda a aquisição de produtos e serviços no mercado quando os custos internos destes forem superiores aos praticados externamente. Se o processo decisório for centrado apenas com base em custos de sua realização, será favorecida a opção de aquisição do serviço de P\&D no mercado, ao invés de sua realização interna. Consequentemente, segundo a mesma vertente teórica, a firma tenderá a ser maior quando os custos de transações internas forem menores do que as realizadas no mercado. 
A firma também deverá optar por fazer P\&D internamente quando as transações forem frequentes, incertas e vierem a demandar investimentos especiais, ou seja, ativos específicos (SWEDBERG, 2003). Do contrário será usado o mercado. No entanto, pode se verificar existência de importantes contrapontos, como, por exemplo, de Alchian e Demsetz (2005) os quais, com base na teoria de agência identificaram acréscimos de custos internos decorrente da necessidade de supervisão e controle de processos internos. Katz e Piepoli (1995); Jones (2000); Anik (2002), Morrison (2002) e Kramer (2002) também evidenciam a predominância de razões econômicas para a decisão de externalizar P\&D apontando, entre outras, para as vantagens de desoneração da estrutura de pessoal e administrativa, em termos de envolvimento do gestor.

Bright (1996); Goel (1999); Ulset (1996); Hertog et al. (1993); Deb (1996) argumentam que a externalização de P\&D proporciona para as empresas as vantagens como a identificação de oportunidades de desenvolvimento de novos produtos, redução de riscos e de valores investidos. Deduzem que a organização que externaliza, ao menos parte de P\&D, poderá obter maior lucratividade advinda do menor tempo de desenvolvimento de produtos inovadores e da possibilidade de gestão simultânea de vários projetos de P\&D. Estes seriam os principais motivos que estariam por trás da transferência de atividades de P\&D na área de software dos Estados Unidos para a Índia (The Economist, 2004) e fazendo com que algumas das organizações pesquisadas por Blanchard et al. (1996) chegassem à participação de oitenta por cento do P\&D externo dentro do orçamento total para P\&D.

Autores que estudam a estratégia, Barney e Hesterly (2004), observam que o desempenho superior de uma firma se apoia em recursos e capacidades, que devem ser valiosos, raros, custosos de imitar e sem substitutos, constituindo assim recursos estratégicos da organização. Ao mesmo tempo verifica-se que a especificidade destes ativos pode dificultar o processo de externalização conforme destacou Williamson (1996) e apontou para a necessidade contratual para reduzir o risco do contratado. Esta situação se aplica diretamente às atividades de P\&D pela especificidade das características de infraestrutura fundamentais para a condução dos processos de pesquisa podendo, desta forma, constituir empecilhos reais para sua externalização.

Boath et al. (1996) destacam como principais vantagens de externalização de P\&D o uso apropriado de recursos flexíveis e mais eficientes, proporcionando a redução de custos. Defendem que a empresa deve focar os esforços de P\&D interno em pesquisas de produtos estratégicos e centrais, externalizando os demais desenvolvimentos, no que são apoiados por Harris et al (1996) que constatam que a externalização de P\&D possibilita atingir maiores índices de produtividade, o que por sua vez implica em riscos de dependência e novas vulnerabilidades e recomendam que a decisão de externalizar P\&D deve ser baseada em seguintes variáveis: a centralidade e importância da pesquisa para a organização, no papel estratégico da competência que provêm da pesquisa e no valor agregado da tecnologia resultante da pesquisa.

Binsacca (2000); Epstein (2000) argumentam que as empresas devem se dedicar às atividades como marketing, produção e gestão e aproveitar ao máximo o conhecimento já 
consolidado junto a institutos de pesquisa. Neste ponto são corroborados por Woodhouse et al. (2002) que percebem em organizações que externalizam as atividades de P\&D evidências de níveis mais elevados de qualidade, competência, capacidade, além de melhor infraestrutura em termos de máquinas e equipamentos. Adotando uma posição mais conservadora, recomenda uma 'dosagem' adequada de atividades de P\&D interno, externo e quase-externo pode prevenir a empresa não apenas de investimento abaixo ou acima do necessário, mas também pode auxiliar na manutenção do seu posicionamento competitivo a longo prazo. Para estes autores a decisão sobre a forma de realizar P\&D deverá também considerar: distribuição de tipos de competências que a empresa possui; evolução de tecnologias individuais e a variação das características da tecnologia à medida que esta se direciona da tecnologia nova para madura, assuntos estratégicos e econômicos relacionados com o ambiente competitivo.

Como contraponto aos posicionamentos e argumentos apresentados pode ser citado o relatório analisado por Johnson (2004), sobre a perspectiva de atividades de P\&D em noventa e oito indústrias associadas a Industrial Research Institute (IRI) nos Estados Unidos, no período de 1999 a 2004, que evidencia que as corporações preferem internalizar a atividade por entender que se trata de uma importante vantagem competitiva estratégica. Percebe-se que a teoria econômica e o enfoque estratégico proporcionam uma base sólida para interpretar os resultados de processo decisório de muitas organizações. No entanto entende-se que o universo multifacetado das organizações e a complexidade dos processos decisórios organizacionais exigem uma base teórica mais completa. Sabe-se que o lado humano das organizações representa a essência da estrutura organizacional e é responsável por caracterizar, em grande parte, o modo de pensar e de agir dos gestores organizacionais. Com base nesta constatação vários autores procuraram contribuir para o debate com estudos da variável confiança, tanto no âmbito intra como inter organizacional.

A pesquisa empírica conduzida por Noveli (2006) pelo método de estudo de caso múltiplo demonstrou que as empresas percebem uma série de fatores contrários à externalização de $P \& D$ com destaque para: atribuição de propriedade de patentes e resultados; duração de projetos; diferentes objetivos da universidade e da empresa; burocracia envolvida na contratação junto a instituição de ensino; o nível de envolvimento da universidade no projeto e grau de incerteza do projeto de P\&D proposto. No entanto os resultados evidenciados não impedem a apresentação de alguns contrapontos como a difícil generalização de algumas das conclusões, dentre as quais se podem destacar a diferenciação dos objetivos da universidade e da empresa, que em vários pontos convergem, em virtude de evidente interesse para desenvolvimento de projetos em conjunto e os trâmites burocráticos que podem ser verificados tanto junto a instituições de ensino como em várias empresas privadas de grande porte.

Jonash (1996) e Carayannis et al. (2000) constatam que maior parte dos gestores responsáveis por $P \& D$ nas empresas reluta em externalizar $P \& D$ devido à falta de controle sobre o processo de desenvolvimento e falta de confiança na contratada. A pesquisa realizada com 
quarenta empresas da Nova Zelândia, sendo 25 de pequeno porte, 10 de porte médio e 5 de porte grande, conduzida por Davenport et al. (1999) revelou que o processo de externalização de P\&D pelas empresas, junto a universidades e institutos de pesquisa, estava sendo influenciado, negativamente, pela falta confiança na competência dos institutos de pesquisa para a execução das atividades previstas e sugerem que a externalização de atividades de $P \& D$ seja examinada à luz da confiança multidimensional. Os resultados da pesquisa de Klofsten et al. (1999) destacam a importância do fator de confiança no processo de interação U-E demonstrando evidências de contratações de serviços de P\&D junto a instituições de ensino e pesquisa em decorrência de contatos informais entre executivos e pesquisadores. A pesquisa de Vardzel (2000) evidencia a influência do porte da empresa contratada (quanto maior melhor) para o sucesso de externalização de P\&D com base na confiança e na qualidade de comunicação entre a contratante e a contratada.

A importância da variável confiança é ressaltada também em pesquisas realizadas no Brasil. Brisolla et al. (1997), da Unicamp, percebem que o processo de externalização de P\&D com as universidades ocorre em virtude de contatos pessoais dos alunos e professores com as empresas, como também Dagnino e Gomes (2003) relatam o caso de interação de uma empresa com a instituição de ensino onde fica evidenciada a valorização, por parte da empresa, do corpo docente, no tocante ao grau de especialização e titulação que transmite uma maior segurança e confiança na competência da universidade.

Para solucionar o problema de confiança nas relações entre contratante e possível contratado, dentro da área de P\&D, notadamente na questão de competência técnica, Griest e Liou (1998) destacam a importância da manutenção de controles do processo de externalização de P\&D para as empresas certificadas pelas normas internacionais de qualidade e recomendam que as empresas: envolvam as empresas contratadas para a realização de P\&D em processo de normatização da ISO e forneçam as condições e orientações à empresa contratada para que a mesma tenha condições de cumprir os requisitos para a implantação e manutenção de processo de qualidade; compartilhem com as empresas contratadas os seus objetivos estratégicos, ou seja, a empresa contratada deve compreender onde a empresa contratante pretende chegar; estabeleçam políticas internas de $\mathrm{RH}$ com vistas a reduzir possível discriminação e desconforto dos colaboradores em relação a pesquisadores externos e exijam o cumprimento de normas e procedimentos legais no processo de P\&D.

A preocupação com a proteção contratual também é verificada no artigo de Chiesa et al. (2000) que sugerem critérios para a seleção e contratação de empresas para a externalização de P\&D, como: identificar uma apropriada unidade de análise, analisar as características de colaboração, eliminar as características não relevantes para o contrato, identificar o conjunto de requisitos prioritários e cruzar os requisitos prioritários com as características organizacionais das diferentes formas de colaboração. As vantagens da existência de um instrumento de contratação também são destacadas por Osmond e Coleman (1999) por entender que o contrato faculta a 
inclusão de cláusulas de saída, ao mesmo tempo em que caracteriza a flexibilidade e complexidade de adaptação a fatores e circunstâncias específicas da parceria. Com o objetivo de complementar as abordagens teóricas anteriores verifica-se que vários autores procuram contribuir para o debate com o argumento baseado em gestão do conhecimento e sua importância para a organização, visando respaldar a opção pela realização de P\&D dentro da organização, ao mesmo tempo em que existem autores que defendem a opção de externalização das atividades pela mesma razão, ou seja, por perceber que a interação com os agentes externos favorece o desenvolvimento de competências internas em P\&D.

É importante destacar que totalidade dos autores pesquisados concorda de que a hipótese de externalização integral das atividades de P\&D se pode considerar inviável, por representar para uma organização a abdicação de um dos recursos centrais da sua operação e potencial fonte de diferencial competitivo. O conhecimento, para Nonaka e Taqueuchi (1997) diz respeito a crenças e compromissos e está relacionado a algum fim. Além disso, o conhecimento refere-se ao significado, ou seja, é específico ao contexto e relacional. No entanto, o ambiente per se não cria conhecimento sem indivíduos, apenas os apóia ou lhes proporciona contextos para a criação de conhecimento. A função da informação no processo de geração de conhecimento é a de proporcionar um novo ponto de vista para a interpretação de eventos ou objetos, tornando visíveis significados e conexões inesperadas.

A pesquisa realizada por Veugelers (1997) atesta, com base em resultados da pesquisa realizada com 290 empresas da Bélgica, no período de 1992 a 1993, que a capacidade absortiva e desenvolvimento de competências técnicas são dependentes de uma sólida infra-estrutura interna em P\&D. Landau (1999) também apresenta dados empíricos que justificam a externalização de P\&D pela necessidade de acesso a novos conhecimentos para aumento da competência técnica interna, além de possibilitar o acesso a novos nichos de mercado, verificam, a partir da pesquisa com 304 empresas inovadoras da Holanda, no período de 1996 a 2001, que as empresas com o P\&D interno estruturado apresentam condições mais adequadas para a absorção de resultados de P\&D contratado externamente.

No entanto, fica evidente que as empresas que externalizam P\&D têm melhores condições de desenvolver as competências internas, interagir com o ambiente externo, combinar conhecimentos e trabalhar em rede. Os resultados da pesquisa conduzida por Hall e Bagchi-Sem (2007) seguiram na mesma direção e evidenciaram que as empresas com mais altos índices de inovação decorrentes de P\&D percebem que seu sucesso de desenvolvimento de competência interna se deve ao relacionamento com as fontes de conhecimento externas, como pesquisadores universitários e outras empresas vinculadas ao setor. Também Quinn (2000) e Nicholls-Nixon e Woo (2003) percebem os benefícios para a gestão do conhecimento por meio da interação com os agentes externos via acesso ao vasto conhecimento externo existente junto a potenciais parceiros, além do potencial estímulo à estruturação ou reestruturação de P\&D interno. Barnes et al. (2006) demonstram que a externalização de P\&D também favorece relacionamentos em nível 
pessoal e em nível organizacional. É possível perceber que autores divergem em vários pontos com base em argumentos apresentados pelas vertentes teóricas analisadas, no entanto entendese que é possível sugerir que a adoção da forma de P\&D depende do contexto conforme demonstra o estudo de Cassiman e Veugelers (2005) onde é destacada a relevância do contexto para a combinação dos conhecimentos de fontes internas e externas. Esta constatação se baseia nos resultados decorrentes da pesquisa realizada com 714 empresas belgas destacando a importância da criação do contexto certo. Ou seja, a gestão cuidadosa do processo de inovação, baseada na compreensão destes princípios, poderá assim constituir uma vantagem competitiva sustentável.

Supõe-se que a caracterização contextual do universo organizacional ainda permite a configuração de situações em que nenhuma das abordagens teóricas é suficiente para explicar a decisão tomada, abrindo espaço para novas abordagens. Entende-se que duas A abordagem teórica escolhida para contribuir ao debate refere-se aos valores organizacionais, que fazem parte da cultura e universo organizacional, onde a área de P\&D e as atividades por ela desempenhadas representam um determinado papel, dentro da intrincada rede de poder organizacional. Pretendese assim completar a análise compreensiva do processo decisório organizacional que procura definir a forma de realizar as atividades de P\&D.

Para Souza (1978) a cultura pode ser dividida em três elementos, cada um abrangendo uma série de fenômenos interdependentes. São eles: preceitos compreendidos como conjunto de normas, valores, regulamentos, política administrativa, tradições, estilos gerenciais, questões formais (leis), assim como costumes, rituais, padrões e aspectos informais que são seguidos tacitamente; tecnologia, sendo entendida como conjunto de instrumentos, processos, layout, distribuição de tarefas, divisão de trabalho e fluxo organizacional subsidiando a função técnica, metodológica científica, racional e operativa da organização; caráter como um conjunto de expressões ativas e afetivas dos indivíduos da organização, manifestações subjetivas, as percepções, os sentimentos e as reações positivas ou negativas dos sujeitos organizacionais características dos comportamentos grupais.

Os processos e rotinas da área de P\&D encontram-se, visivelmente, respaldadas no conceito apresentado pelo Souza (1978) por se tratar, atualmente, de uma das unidades organizacionais que está mais sujeita a procedimentos e normatização, dentro da organização, da mesma forma como a tecnologia compreendida em processos operacionais. O terceiro fator citado pelo autor, referente a expressões ativas e afetivas está presente em toda organização, e também na área de P\&D, na sua dimensão subjetiva e, portanto, nem sempre reconhecida, em virtude do foco mais objetivo de seus processos. Neste sentido se faz importante a contribuição de Shein (1988) que estuda o papel do grupo de indivíduos que influenciam e moldam a cultura organizacional compreendendo, desta forma, a cultura organizacional como um conjunto de pressupostos básicos que um grupo inventou, descobriu ou desenvolveu ao aprender como lidar com os problemas de adaptação externa e integração interna. Estes pressupostos funcionaram 
bem o suficiente para serem considerados válidos e assim passam a ser ensinados a novos membros como forma correta de perceber, pensar e sentir em relação a esses problemas.

Shein (1988) apresenta, também, o processo, por meio do qual ocorre a aprendizagem cultural, que segundo ele ocorre em vários níveis: nível dos artefatos visíveis, que são de fácil percepção, mas de difícil interpretação, como, por exemplo, o comportamento das pessoas, o layout da empresa, os documentos; nível dos valores que governam o comportamento das pessoas onde existem diferenças entre os valores aparentes e os valores de uso; nível dos pressupostos básicos, que são geralmente inconscientes, mas demonstram como os membros de um grupo percebem, pensam e sentem.

\section{Os Paradigmas e a Representação da Realidade}

A concepção do pensamento complexo por Morin (2002) apresenta a constatação de que os paradigmas inovadores são fortemente enfocados na visão de totalidade, de interconexão, de inter-relacionamento, na superação da visão fragmentada do universo e na busca da reaproximação das partes para reconstituir o todo nas variadas áreas do conhecimento. Morin (2003) argumenta que uma sociedade é mais que um contexto: é o todo organizador de que fazemos parte. O todo tem qualidades ou propriedades que não se encontram nas partes, se estas não estiverem isoladas umas das outras e certas qualidades ou propriedades das partes podem ser inibidas pelas restrições provenientes do todo é preciso efetivamente recompor o todo para conhecer as partes.

Ao mesmo tempo percebe-se que o reconhecimento da complexidade do mundo e de suas características multifacetadas está presente no nosso cotidiano na medida em que os meios de comunicação de massa se apoderam do tema e propagam através de todas as formas disponíveis a sua interpretação dos acontecimentos à luz de diversas ideologias a serviço das quais se encontram. É possível verificar o avanço da ciência social no tocante à cristalização de correntes de pensamento que permitem o desenvolvimento de estudos e pesquisas sob os principais paradigmas vigentes e suas dimensões ontológicas, epistemológicas e metodológicas procurando aperfeiçoar a prática da ciência e minimizar a ocorrência do viés do pesquisador.

No entanto constata-se que ainda existe uma tendência dos cientistas e pesquisadores sociais de adotar determinados paradigmas, decorrentes do seu posicionamento ideológico individual, influenciando, destarte, desde a escolha do problema de pesquisa, passando por definição do universo de pesquisa, método e até a identificação e mensuração de evidências e interpretação de resultados. Considerando-se o desafio do pesquisador de representar a realidade fica evidente a necessidade de concepção metodológica que possa minimizar os efeitos da influência do posicionamento paradigmático sobre os resultados obtidos.

Cada um dos paradigmas vigentes (positivismo, pós-positivismo, teoria crítica, construtivismo e teoria participatória) apresenta diferenças significativas nas dimensões 
ontológicas, epistemológicas e metodológicas, de difícil conciliação. Consequentemente, ao assumir um determinado posicionamento, o pesquisador opta por um conjunto específico de métodos de pesquisa, de natureza quantitativa ou qualitativa, muitas vezes percebendo o problema de pesquisa pelas lentes do método, de forma oposta ao processo científico de pesquisa, reproduzindo modelos, evidências e resultados. Este tipo de prática de pesquisa não apenas deixa de contribuir para o conhecimento científico, como também permite questionamento quanto à sua validade.

Desta forma pode-se afirmar que além da complexidade dos fenômenos sociais a própria escolha do método de pesquisa constitui um desafio relevante ao se considerar a importância de lentes teóricas (paradigma) que o pesquisador utilizará para definir o método de pesquisa e para a interpretação de seus resultados. Diante deste desafio torna-se essencial a competência do pesquisador de transitar por diversos paradigmas em vigor, quebrando barreiras e pré-conceitos em relação a dimensões ontológicas, epistemológicas e metodológicas, focando a sua atenção para o problema de pesquisa e adotando o método que apresenta melhores condições de explicar e compreender o referido fenômeno. Assim poderá ser reduzida a influência do paradigma subjacente à percepção das variáveis e fatores que fazem parte do fenômeno social em estudo. Desta forma haverá impacto direto na escolha do método de pesquisa, influindo tanto na tipificação das evidências encontradas, como da interpretação de seus resultados.

Esta influência da opção paradigmática e suas respectivas dimensões ontológicas e epistemológicas estão presentes, notadamente, em processo de pesquisa qualitativa, onde o pesquisador encontra-se em relação ativa e atuante com o objeto pesquisado, ator e coadjuvante do processo, com chances reduzidas de uma ingênua neutralidade. Destarte é possível aquilatar a importância do processo de reflexão compreensiva do tema de condução do processo de pesquisa, em especial de pesquisa qualitativa, da validade de sua escolha e operacionalização em face aos fenômenos em estudo. As transformações conceituais das relações sociais, decorrentes do reconhecimento da estrutura social multifacetada e complexa presente e evidenciada não apenas na cultura ocidental como em outras culturas, várias delas tradicionalmente fechadas e moldadas por princípios religiosos ou políticos, exigem dos cientistas e pesquisadores adoção de novos posicionamentos metodológicos que possibilitem a compreensão da realidade e sua representação mais fiel e isenta possível, de pressupostos individuais do pesquisador.

\section{A Confluência dos Métodos de Pesquisa}

A evolução da ciência é vista por Kuhn (2001) como que seguindo um modelo geral dentro do qual se diferenciam duas fases: a pré-paradigmática e a pós-paradigmática. Sob esta ótica Kuhn (2001) explica o progresso da ciência por revoluções científicas, rupturas radicais com o modelo teórico vigente até então ou ainda a tradição científica estabelecida em determinado 
campo de pesquisa. Esta forma de ver a evolução e o progresso da ciência contesta a corrente teórica que percebe a evolução da ciência como o processo cumulativo de conhecimento. De acordo com Kuhn (2001) a observação e a experiência podem e devem restringir a extensão das crenças admissíveis, mas não possa, por si só, determinar um conjunto específico de semelhantes crenças.

Já os autores Burrell e Morgan (1979) dividiram o campo da teoria organizacional em quatro paradigmas (humanista radical, estruturalista radical, funcionalista e interpretativo), de maneira que o conhecimento do mundo social pode ser concebido como sendo objetivo ou subjetivo e também em termos de ordem e conflito. As teorias de regulação apresentam a visão de que as sociedades modernas se caracterizam mais pela ordem do que por conflitos. Por outro lado, as teorias de mudanças radicais oferecem a interpretação de que as relações sociais são condicionadas mais por pressões contraditórias objetivando transformações do que por forças de continuidade e transformação.

No entanto Guba e Lincoln (2005) apresentam as características dos cinco paradigmas vigentes, ou seja, o positivismo, pós-positivismo, teoria crítica, construtivismo e participatório, retratando-os nas dimensões ontológica, epistemológica e metodológica, destacando suas contradições e analisando as possibilidades da confluência dos mesmos. A priori fica evidente o distanciamento ideológico dos paradigmas analisados, razão pela qual a confluência fica obstaculizada por uma série de variáveis e fatores. Apesar desta constatação, Guba e Lincoln (2005) e Mason (2006) defendem o argumento que acena com a possibilidade de flexibilização dos limites teóricos entre os paradigmas, verificando a possibilidade de influência de um sobre o outro.

Com o objetivo similar, isto é, o de defender o argumento de combinação de métodos de pesquisa de natureza quantitativa e qualitativa, Mason (2006) parte de duas premissas básicas. A primeira deriva da constatação de que a experiência social e realidades vividas são multidimensionais e desta forma se analisados sob apenas um determinado paradigma resultará numa compreensão muito limitada e, muito provavelmente, inadequada, da realidade. Isso ocorre em virtude da composição dos relacionamentos por elementos de natureza emocional, espiritual, imaginária, rotinizada, acidental, sensorial, temporal, espacial, biogenética, cinestésica, virtual, entre outras, combinados em diferentes graus de intensidade. A segunda premissa se refere ao dualismo de escalas micro e macro, presentes em construções científicas incluindo as análises e estudos do público e privado, coletivo versus individual, entre outros. Constata-se que as dimensões micro e macro estão vinculados de forma que a realidade macro pode ser compreendida por meio do processo de análise em nível micro e vice-versa.

A centralidade dos axiomas (valores) como base para a construção do processo de pesquisa, presente desde a escolha do problema, passando pela seleção do paradigma é ressaltada por Guba e Lincoln (2005) por servir de lente filosófica para analisar o problema, do modelo teórico, da técnica de coleta de dados e dos métodos analíticos, do contexto, tratamento 
dos valores já presentes no contexto, até a escolha do modo de apresentação das evidências e dos resultados. Mason (2006) contribui para o debate destacando que as divisões entre os paradigmas não podem ser fixas e estáticas, devido ao fato de que as mesmas não são tão nítidas e precisas.

Destarte é possível afirmar que a incomensurabilidade paradigmática decorre da idiossincrasia axiomática e não da incompatibilidade metodológica. Como exemplo pode se citar o caso da maior afinidade dos métodos de pesquisa qualitativa dentro do paradigma naturalista justificada pela sua adequação para lidar com o ser humano como instrumento. Guba e Lincoln (2005) percebem a possibilidade de comensurabilidade e compartilhamento de modelos e métodos quando existe a similaridade de elementos axiomáticos. Como exemplo os autores citam a comensurabilidade entre os paradigmas positivista e pós-positivista e entre os paradigmas de teoria crítica, construtivista e participatório. Mason (2006) vai mais além e argumenta que usando os métodos criativamente combinados é possível reunir dados e informações que podem servir de base para construir teoria social adequadamente embasada e respaldada em experiência empírica e significativa.

Ao analisar as diversas fontes de controvérsias entre as abordagens paradigmáticas emerge o papel ativo do pesquisador no processo de pesquisa, o qual é considerado inaceitável dentro do paradigma positivista e pós-positivista, por representar o potencial risco de contaminação de dados e de perda de objetividade (GUBA \& LINCOLN, 2005). Esta posição é contestada pelas correntes alinhadas com paradigmas de teoria crítica, construtivista e teoria participatória, por entender que o papel mais ativo do pesquisador favorece a compreensão do contexto em estudo. Bourdieu (2001) corrobora este entendimento e interpreta a relação de pesquisa como sendo uma relação social que exerce efeitos sobre os resultados obtidos e entende que todo tipo de distorções estão inscritas na própria estrutura na relação de pesquisa.

No tocante ao controle do estudo Guba e Lincoln (2005) expressam o entendimento que o mesmo é essencial nas questões de voz, reflexividade e representação textual pós-moderno. Para os pesquisadores da linha convencional, no entanto, este controle significa o risco potencial de perda do rigor científico, em especial de objetividade e validade. Vale destacar que esta percepção não é compartilhada por pesquisadores que seguem os novos paradigmas para quem o risco está justamente na não intervenção (BOURDIEU, 2001). Pode ser citado, a título de exemplo, que para Bourdieu (2001) a reflexividade reflexa permite perceber e controlar no campo, na própria condução da entrevista, os efeitos da estrutura social na qual ela se realiza.

A questão ontológica de representação da realidade também apresenta posicionamentos divergentes entre os paradigmas, em particular, no aspecto relativo aos métodos de pesquisa e de seu impacto sobre a interpretação das evidências e dos resultados, da mesma forma como o significado do que é a verdade (GUBA \& LINCOLN, 2005). Neste ponto a constatação é corroborada por Mason (2006) que também verifica que as questões de pesquisa encontram-se vinculadas às perspectivas ontológica e epistemológica que embasam o processo de pesquisa, 
além de argumentar que os fenômenos multifacetados dificultam a tomada de seleção entre métodos qualitativos ou quantitativos.

Contrariamente à percepção à qual tendem muitos pesquisadores sociais, a pesquisa quantitativa pode oferecer contribuições significativas em pesquisa social, tais como concepção de modelos teóricos de maior amplitude, além de prever tendências e médias. A pesquisa qualitativa, por sua vez, oferece melhores condições para explorar em profundidade os contextos de situações sociais específicas, além de realizar comparações dos processos similares em outros contextos ou contextos similares e processos semelhantes, com fins de geração de explanações.

Guba e Lincoln (2005) percebem que a validade não está respaldada em aplicação de um método apenas ou tampouco é garantida pela combinação de vários métodos. Aliás, o tema de validade mereceu uma atenção especial dos autores em virtude de suas possíveis interpretações, tais como a análise da validade como autenticidade, resistência, transgressão pós-estruturalista, relacionamento ético e pelo risco de multiplicidade de critérios de pesquisa que a reconfiguração do conceito de validade pode gerar. Ao analisar a validade como autenticidade Guba e Lincoln (2005) destacam cinco potenciais critérios de pesquisas sociais, cada um baseado em paradigmas específicos: assertividade, autenticidade ontológica, educativa, catalítica e tática.

A validade, de fato, não pode ser entendida como algo imutável, permanente e fixo e sim deve ser interpretada à luz da complexidade do mundo e de suas várias e possíveis interpretações, ou seja, é contextual e situacional. Nesta linha, Guba e Lincoln (2005) conduzem as reflexões da validade como resistência e transgressão pós-estrutural, que se reflete no embasamento conceitual da validade como o relacionamento ético, ou como os autores colocam: "o modo de como sabemos está certamente vinculada ao o que sabemos e de como nos relacionamos com os participantes de pesquisa" (GUBA \& LINCOLN, 2005, p.209). Bourdieu (2001) demonstra a mesma preocupação ao recomendar ao pesquisador social se esforçar para, ao menos, compreender o que pode ser dito e o que não pode, já que a própria pesquisa pode ser interpretada como uma espécie de intrusão sempre um pouco arbitrária durante a qual o pesquisado assume uma determinada posição, com base no seu entendimento do sentido da pesquisa, da situação e da relação com o pesquisador.

Como exemplo pode ser relatada a avaliação de Guba e Lincoln (2005) e Bourdieu (2001) da questão da voz e sua importância na transcrição, devido a possíveis e diversos significados na interpretação de lapsos, das pausas, das paradas e reformulações de respostas constantes das pesquisas qualitativas, como também de suas formas textuais e múltiplas dimensões. Neste sentido Bourdieu (2001) afirma que a proximidade social e a familiaridade configuram condições para realização de uma comunicação 'não violenta'. Recomenda, também, recorrer a estratégias como a que consiste em representar papéis, compor identidade de um pesquisado ocupando uma posição social e cita como exemplo o caso do estudo sobre o modo de falar dos negros de Harlem, onde o pesquisador pediu a jovens negros conduzir a pesquisa linguística. 
$\mathrm{Na}$ interpretação da importância da reflexividade, ou seja, da necessidade do pesquisador de se situar dentro do processo de pesquisa Guba e Lincoln (2005) apontam para a existência de múltiplas identidades do pesquisador como o instrumento humano. É evidente que o pesquisador, ao mesmo tempo em que influencia, no contexto de pesquisa, também é influenciado. Esta constatação é corroborada por Foucault (2005) quando o mesmo afirma que a constituição do sujeito, numa dada cultura, se processa através de determinadas práticas e discursos. Dentro desta concepção surge à questão do indivíduo como efeito do poder e, simultaneamente, seu centro de transmissão, ou seja, o poder passa através do indivíduo que ele constituiu.

Neste sentido cabe analisar melhor as relações de poder que permeiam o ambiente organizacional. Para Foucault (2002) o poder não se localiza aprioristicamente em uma única instância, mas se expressa de várias formas - os micropoderes - enquanto práticas sociais, ao nível do próprio cotidiano. O poder microfísico não está subordinado a nada, manifesta-se em multiplicidade de formas e é produtor de realidades e coisas. As práticas discursivas se constituem de elementos teóricos que integram o poder normalizador - discursos científico, filosófico, religioso, entre outros. As técnicas de controle corporal, regulamentos administrativos de controle do tempo dos indivíduos e das próprias instituições, técnicas e métodos de organização espacial, entre outros, representam, por sua vez, os elementos não discursivos ou práticas desse poder (FOUCAULT, 2005).

Para Bourdieu (2001) deve-se exercer ação sobre a própria estrutura da relação (estrutura linguística e simbólica), ou seja, na seleção de pesquisadores e dos pesquisados. Na relação entre o pesquisado e o pesquisador verifica-se a possibilidade de surgimento de um jogo velado, onde cada um joga o jogo do outro, enganando a si e o outro, ao mesmo tempo. Além disso, existe a possibilidade de falsa autenticidade quando o entrevistado, por várias razões ou carência, aproveita a oportunidade de ser ouvido, para construir a sua própria história. Bourdieu (2001) alerta também para o 'jogo de leitura' onde existe o risco de construção de textos que podem exercer a influência simbólica e paradigmática, exigindo a intervenção do analista. Atividade, que na percepção do autor, representa um elevado grau de complexidade.

\section{CONCLUSÕES}

A realidade do mundo, em toda a sua complexidade constitui para os pesquisadores sociais um desafio relevante. Multifacetada e multidimensional, a realidade permite diversas interpretações à luz de axiomas predominantes. Axiomas que embasam a edificação dos principais paradigmas que, por sua vez, orientam a construção das dimensões ontológica, epistemológica e metodológica da ciência social. No entanto a representação da realidade percebida, em toda a sua complexidade, sugere que a utilização de lentes teóricas de apenas um só paradigma reproduz uma versão empobrecida da realidade existente, colocando em risco as evidências e os resultados da pesquisa realizada. 
Com o objetivo de contribuir para o debate sobre novas possibilidades de retratar a realidade, por meio de combinações de métodos de pesquisa qualitativa e quantitativa, foram analisados textos de três autores, com o intuito de identificar as principais tendências e verificar as perspectivas futuras. Foi possível perceber que existe a comensurabilidade entre paradigmas que compartilham axiomas semelhantes, como é o caso do positivismo e pós-positivismo, e entre a teoria crítica, construtivismo e a teoria participatória. Neste caso as dimensões ontológica, epistemológica e metodológica apresentam características que permitem combinações, segundo Guba e Lincoln (2005) e Mason (2006) rompendo barreiras tradicionais que separavam de forma mais impermeável os paradigmas entre si, abrindo caminho para conversações entre os paradigmas.

A análise permitiu identificar que as pesquisas de natureza qualitativa e quantitativa podem contribuir para a prática da ciência social, de acordo com as suas características. Foram analisados aspectos relacionados ao papel do pesquisador e tendência do mesmo de adotar certos posicionamentos paradigmáticos que norteam sua ação, desde a escolha do problema pesquisado, do método de pesquisa, até a identificação de evidências, apuração dos resultados e sua interpretação à luz do paradigma escolhido.

Foi analisado também o processo de pesquisa qualitativa, onde o pesquisador influencia e é influenciado e está sujeito a uma série de variáveis decorrentes da relação construída com o pesquisado. Portadores de identidades múltiplas, o pesquisador e o pesquisado, ambos colocam dentro da relação uma série de expectativas e recebem a oportunidade de contribuir para a reconstrução de suas percepções em relação a si e em relação a outro. Constatou-se, também, que o poder é exercido através de micro-relações que perpassam o cotidiano e os indivíduos e que o sujeito, como o centro produtor e transmissor de poder, está sempre em posição de exercer o poder e sofrer a ação deste mesmo poder, a partir da constituição de seus discursos.

Revisando a literatura percebe-se que provavelmente inexiste a 'verdade única' e isto sim, que todas as verdades são verdades parciais, ou seja, as pesquisas que pretendem representar a realidade conseguem captar e retratar apenas parcialmente os fatos estudados contidos na realidade pesquisada. Destarte é possível dizer que não é recomendado trabalhar dentro de apenas um único paradigma, constituindo o desafio aos pesquisadores e cientistas sociais a combinação de vários métodos, com o intuito de ser mais fiel à realidade dos fatos e evidências estudados.

\section{REFERENCIAS}

ALCHIAN, A. A.; DEMSETZ, H.. Produção, custos de informação e organização econômica. Revista de Administração de Empresas, v.45, n.3, p.70-92-108, 2005.

ANIK, S. T.. A new map for creating sustainable competitive advantages. Pharmaceutical Technology North America, 2002.

BARNES, T A.; PASHBY, I. R.; GIBBONS, A. M.. Managing collaborative R\&D projects development of a practical management tool. International Journal of Project Management, v.24, p. 395-404, 2006. 
BARNEY, J. B.; HESTERLY, W.. Economia das organizações: entendendo a relação entre organizações e a análise econômica. Handbook de estudos organizacionais. São Paulo: Atlas, 2004.

BLANCHARD, K. H.; HERSEY, P.; JOHNSON, D.. Management of Organizational Behavior: Utilizing Human Resources. Englewood Cliffs: Prentice Hall, 1996.

BOATH, D.; HESS, P.; MUNCH, C.. Virtual R\&D: A core competency approach to outsourcing.

Pharmaceutical Executive, v.16, n.6, p.72-84, 1996

BOURDIEU, P.. A miséria do mundo. Petrópolis: Vozes, 2001.

BOYLE, T. A.; KUMAR, U.; KUMAR, V.. Organizational contextual determinants of cross-functional NPD team support. Team Performance Management, v.11, n.1, p.27-33, 2005

BRIGHT, J.. Continued growth in outsourced R\&D. Telecommunications, v.30, n.3, p.26-34, 1996.

BRISOLLA, S.; CORDER, S.; GOMES, E.; MELLO, D.. As relações universidade-empresa-governo: um estudo sobre a Universidade Estadual de Campinas (Unicamp). Educação \& Sociedade, v.8, n.61, 1997.

BURREL, G.; MORGAN, G.. Sociological paradigms and organizational analysis. London: Heineman, 1979.

CARAYANNIS, E. C.; ALEXANDER, J.; IOANNIDIS, A.. Leveraging knowledge, learning and innovation in forming strategic government-university-industry (GUI) R\&D partnerships. Technovation, v. 20, p.477-488, 2000.

CASSIMAN, B.; VEUGELERS, R.. In search of complementarity in the innovation strategy: Internal R\&D and external knowledge acquisition. Leuven: University of Leuven, 2005.

CHIESA, V.; MANZINI, R.; TECILLA, F.. Selecting sourcing strategies for technological innovation: an empirical case study. International Journal of Operations \& Production Management, Bradford, v. 20, n. 9, p.1017-1021, 2000

COASE, R. H.. The nature of the firm. Economica, v.4, n.16, p.386-405, 1937.

COOPER, R.. Open field. Human Relations, v.29, n.11, p.999-1017, 1976.

DAGNINO, R.. A relação universidade-empresa no Brasil e o "argumento da hélice tripla". Revista Brasileira de Inovação, v.2, n. 2, p. 267-307, 2003.

DAGNINO, R.; GOMES, E.. A relação Universidade-Empresa: comentários sobre um caso atípico. Gestão \& Produção, v.10, n.3, p.283-292, 2003.

DAVENPORT, S.; DAVIES, J.; GRIMES, C.. Collaborative research programmes: building trust from difference. Technovation, v.1, p.31-40, 1999.

DEB, C.. Accessing external sources of technology. Research Technology Management; v.2, p.48-56, 1996.

EPSTEIN, L. M..Results of the contract laboratory services 2000 - survey. Pharmaceutical Technology, Cleveland, v.24, n.6, p.88-99, 2000.

FOUCAULT, M.. A ordem do discurso. São Paulo: Loyola, 2005.

FOUCAULT, M.. Vigiar e punir: história da violência nas prisões. 25 ed. Petrópolis: Vozes, 2002.

GOEL, R. K.. On contracting for uncertain R\&D. Managerial and Decision Economics, v.20, n.2; p.99-110, 1999.

GRIEST, D. L.; LIOU, A.Y. H.. The impact of contracting on quality transformation in R\&D. Quality Progress, v.31, n.5, p.75-81, 1998

GUBA, E. G.; LINCOLN, Y. S.. Paradigmatic controversies, contradictions, and emerging confluences.

London: Sage, 2005. 
HALL, L. A.; BAGCHI-SEM, S.. Na analysis of firm-level innovation strategies in the US biotechnology industry. Technovation, v.27, p.4-14, 2007.

HARRIS, R. C.; RICHARD, C.; MORONE, J.; WERLE, M. J.. The virtual R\&D laboratory. Research Technology Management, v.39, n.2, p.32-45, 1996.

HERTOG, D.; THURIK, R. G. J. R. A.. Determinantes of internal and external R\&D: some dutch evidence. The Economist, v.141, n.2, p.278-283, 1993.

HOWELLS, J.. Research and technology outsourcing. Technology Analysis \& Strategic Management, v.11, n.1, p.17-25, 1999.

JOHNSON, A. L.. Industrial Research Institute's R\&D Trends Forecast for 2004. Research Technology Management, v.47, n.1, p.17-25, 2004.

JONASH, R. S.. Strategic technology leveraging: making outsourcing work for you. Research Technology Management, v.39, n.2, p.19-25,1996.

JONES, O.. Innovation Management as a Post-Modern Phenomenon: the outsourcing of pharmaceutical R\&D. British Journal of Management, v.11, p.341-356, 2000.

KATZ, P. H.; PIEPOLI, M.. Drug \& Cosmetic Industry. New York: Apr, 1995.

KLOFSTEN, M.; JONES-EVANS, D.; SCHARBERG, C.. Growing the Linkoping Technopole - A Longitudinal Study of Triple Helix Development in Sweden. Journal of Technology Transfer, v. 24, n.2-3, p.125-135, 1999

KRAMER, G.. Outsourcing R\&D. Appliance Manufacturer, v.19, n.5, p.743-767, 1998.

KUHN, T. S.. A estrutura das revoluções científicas. 3 ed. São Paulo: Perspectiva. 2001.

LANDAU, P.. TFF in R\&D outsourcing link with beverage maker Phlo Corp. Chemical Market Reporter, v.18, n.16, p.18-25, 1999.

LANGLOIS, R. N.. The vanishing hand: the changing dynamics of industrial capitalism. Industrial and Corporate Change, v.12, n.2, p.351-885, 2003.

MADHOK, A.. The organization of economic activity: transaction costs, firm capabilities, and the nature of governance. Organization Science, v.7, n.5, p.577-590, 1996.

MARDSEN, R.; TOWNLEY, B.. A coruja de Minerva: reflexões sobre a teoria na prática. São Paulo: Atlas, 2001.

MASON, J.. Mixing methods in a qualitative driven way. Marketing Inteligence \& Planning, v.10, n.9, p.1020, 1992.

MORIN, E.. A cabeça bem-feita: repensar a reforma, reformar o pensamento. Rio de Janeiro: Bertrand Brasil, 2001.

MORIN, E.. Os Sete saberes necessários à educação do futuro. 8 ed. São Paulo: Cortez, 2003

MORIN, E.; CLOTET, J.. As Duas globalizações: complexidade e comunicação: uma pedagogia do presente. 2 ed. Porto Alegre: Sulina Universitária, 2002

MORRISON, S.. Outsourcing growth keeps prognosis upbeat. Chemical Week. New York: Feb 27, 2002.

MORT, J. .Nature, value and pursuit of reliable corporate knowledge. Journal of Knowledge Management; v.5, n.3, p.222-230, 2001.

NICHOLLS-NIXON, C. L.; WOO, C. Y.. Technology sourcing and output of established firms in a regime of encompassing technological change. Strategic Management Journal, v.24, n.7, p.651-661, 2003.

NONAKA, I.; TAKEUCHI H.. Criação de conhecimento na empresa: como as empresas japonesas geram a dinâmica da inovação. Rio de Janeiro: Campus, 1997. 
NOVELI, M.. Cooperações tecnológicas universidade-empresa em parques tecnológicos: estudo de casos múltiplos no tecnopuc. Dissertação (Mestrado) - Universidade Federal do Paraná, Curitiba, 2006.

O'CONNOR, G. C.; AYRES, A. D.. Building a Radical Innovation Competency. Research Technology Management, v.48, n.1, p.23-33, 2005.

ORTIZ, R.. Mundialização e cultura. São Paulo: Brasiliense, 2003.

OSMOND, R.; COLEMAN, G. D.. Can single sourcing work in R\&D? Quality Progress, v.32, n.5, p.37-45, 1999.

QUINN, J. B.. Outsourcing innovation: The New Engine of Growth. Sloan Management Review, v.41, n.4, p.13-25, 2000.

SCHEIN, E. H.. Organization Culture and Leadership. San Francisco: Jossey Bass, 1988.

SCHUMPETER, J. A.. Teoria do desenvolvimento econômico: uma investigação sobre lucros, capital, crédito, juro e o ciclo econômico. São Paulo: Abril Cultural, 1982.

SCOTT, R. W.. Institutions analysis: variance and process theory approach. London: Sage, 1994.

SOUZA, E. L. P.. Clima e Cultura organizacional: como se manifestam e como se manejam. São Paulo: Edgard Blücher, 1978.

STOKES, D. E.. O Quadrante de Pasteur: a ciência básica e a inovação tecnológica. Campinas: Editora Unicamp, 2005.

SWEDBERG, R.. Economic versus sociological approaches to organization theory. Oxford: Oxford University Press, 2003.

ULSET, S.. R\&D outsourcing and contractual governance: Na empirical study of commercial R\&D projects. Journal of Economic Behavior \& Organisation, v.30, p.63-82, 1996.

VARDZEL, G. J.. Trust: The secret of success for contract research organizations. Cleveland: Pharmaceutical Technology, 2000.

VEUGELERS, R.. Internal R\&D expenditures and external technology sourcing. Research Policy, v.26, p.303-315, 1997.

WEBER, M.. Economia e Sociedade: fundamentos da sociologia compreensiva. Brasília: UnB, 1999,

WESTWOOD, A. R. C.; SEKINE, Y.. Fostering Creativity and Innovation in an Industrial R\&D Laboratory. Research Technology Management, v.31, n.4, p.16-28, 1988.

WILLIAMSON, O. E.. Economics and organization: a primer. Califórnia Management Review, v.38, n.2, p.131-146, 1996.

WOODHOUSE, R. N.; CUMMINGS, H. R.; FEINGERG, T. N.. The pharmaceutical development of inhalation medicines and the value of outsourcing. Pharmaceutical Technology North America, v.26, n.5, p.26-35, 2002. 